\title{
TWO NEW LATE-TYPE DEGENERATES: IMPLICATIONS FOR THE WHITE DWARF LUMINOSITY FUNCTION
}

\author{
Conard C. Dahn, David G. Monet and Hugh C. Harris \\ U. S. Naval Observatory \\ Flagstaff, Arizona 86002
}

\section{INTRODUCTION}

Recent preliminary USNO CCD parallax solutions for over 100 fields have yielded relative parallaxes with formal errors less than 0 "'0030 for approximately 60 faint $(15.9 \leq \mathrm{V} \leq 20.3)$ stars. The stars observed include a variety of late-type dwarfs, extreme subdwarfs, and degenerates. Among the latter are the well-known, spectroscopically confirmed degenerates LP543-32/33 (= LHS239/240), LP131-66 (= LHS342), LP754-16 (= LHS483), LP702-7 (= LHS542), LP374-4 (= LHS2364), and LP322-800 (= LHS2673), all of which have $M_{v} \geq 15.0$. In addition, two "new" (in terms of previously lacking both spectroscopic confirmations and absolute luminosity estimates) late-type degenerates were identified - LP53-7 (= LHS1405) and LP550-178 (= LHS2288) - both with proper motions in the range 0":700 $\leq \mu \leq 0$ ".799 $\mathrm{yr}^{-1}$.

The white dwarf luminosity function (WDLF) presented by Liebert et al. (1988) and updated slightly in Liebert et al. (1989) employed a $1 / \mathrm{V}_{\max }$ solution for the 43 degenerates contained in the LHS Catalogue (Luyten 1979) which have $\mu \geq 0$ "'800 $\mathrm{yr}^{-1}, \delta \geq-20^{\circ}$, and $\mathrm{M}_{\mathrm{v}} \geq 13.0$ (hereafter, referred to as the ">8tenths" sample). The most important feature of the derived WDLF is an apparent sharp falloff for $\log \left(\mathrm{L} / \mathrm{L}_{\odot}\right)<-4.4$, corresponding to approximately $\mathrm{M}_{\mathrm{bol}}>15.6$ or $M_{v}>16.5$. The identification of LHS1405 and LHS2288 as two new degenerates with $M_{v} \geq 15.0$ among the LHS stars with 0 " $700 \leq \mu \leq 0$ "'799 $\mathrm{yr}^{-1}$ and $\delta \geq-20^{\circ}$ (hereafter, the "7tenths" sample) raises the possibility of augmenting the $>8$ tenths sample and thereby improving the statistics of the WDLF determination near the apparent falloff. Success will depend, of course, on the completeness achieved in distinguishing degenerates from non-degenerates within the 7 tenths sample.

\section{THE 7TENTHS SAMPLE}

The LHS Catalogue contains a total of 320 stars within the 7 tenths sample. Astrometry, photometry and/or spectroscopy are available in the published literature to establish reliable degenerate versus non-degenerate discriminations for 212 of these objects. Unpublished data, either obtained at USNO or communicated privately to us by various colleagues (e.g., P. Hintzen, 
J. Liebert, and R. Probst), establish the nature of an additional 37 stars. Basic data for the eleven stars regarded as established degenerates are collected in Table 1, where an asterisk indicates that a specific explanation is included in the following text. The adopted parallaxes given to four decimal places indicate trigonometric determinations and the values quoted for LHS1341,

TABLE 1

Established White Dwarfs in the 7Tenths Sample

\begin{tabular}{|c|c|c|c|c|c|c|c|}
\hline $\begin{array}{l}\text { LHS } \\
\text { WD }\end{array}$ & $\begin{array}{l}\text { P.M. } \\
\text { Vtan }\end{array}$ & $\begin{array}{l}\mathrm{Pi} \\
\text { m.e. }\end{array}$ & $\begin{array}{c}\mathrm{V} \\
\text { m.e. }\end{array}$ & $\begin{array}{c}\text { B-V } \\
\text { m.e. }\end{array}$ & $\begin{array}{l}\text { V-I } \\
\text { m.e. }\end{array}$ & $\begin{array}{l}\text { n,n, n } \\
\text { Sp. }\end{array}$ & $\begin{array}{l}\mathbf{M}_{\mathbf{v}} \\
\text { m.e. }\end{array}$ \\
\hline $\begin{array}{l}1038 \\
0009+501\end{array}$ & $\begin{array}{r}0.718 \\
37\end{array}$ & $\begin{array}{l}0.0908 \\
0.0037\end{array}$ & $\begin{array}{r}14.36 \\
0.01\end{array}$ & $\begin{array}{l}0.42 \\
0.01\end{array}$ & 0.57 & $\begin{array}{l}\text { 4,4,1 } \\
\text { DA8 }\end{array}$ & $\begin{array}{r}14.15 \\
0.09\end{array}$ \\
\hline $\begin{array}{l}1244 \\
0121+401\end{array}$ & $\begin{array}{r}0.712 \\
103\end{array}$ & $\begin{array}{l}0.0329 \\
0.0055\end{array}$ & $\begin{array}{r}17.10 \\
0.02\end{array}$ & $\begin{array}{l}0.82 \\
0.06\end{array}$ & & $\begin{array}{l}\text { 4,4,-- } \\
\text { DC9 }\end{array}$ & $\begin{array}{r}14.69 \\
0.36\end{array}$ \\
\hline $\begin{array}{l}1341 \\
0203+184\end{array}$ & $\begin{array}{r}0.799 \\
141\end{array}$ & $\begin{array}{l}0.0268 \\
0.0010\end{array}$ & $\begin{array}{c}17.8^{*} \\
0.3\end{array}$ & & & & $\begin{array}{r}14.9 \\
0.3\end{array}$ \\
\hline $\begin{array}{l}1405 \\
0222+648\end{array}$ & $\begin{array}{r}0.727 \\
109\end{array}$ & $\begin{array}{l}0.0316 \\
0.0014\end{array}$ & $\begin{array}{r}18.34 \\
0.01\end{array}$ & & $\begin{array}{l}1.23 \\
0.03\end{array}$ & $2,-, 2$ & $\begin{array}{r}15.84 \\
0.10\end{array}$ \\
\hline $\begin{array}{l}1433 \\
0239+167\end{array}$ & $\begin{array}{r}0.708 \\
168\end{array}$ & $\begin{array}{l}0.020 p \\
0.005\end{array}$ & 17.05 & 0.37 & 0.91 & $1,1,1$ & $\begin{array}{c}13.6 \mathrm{p} \\
0.5\end{array}$ \\
\hline $\begin{array}{l}1693 \\
0437+093\end{array}$ & $\begin{array}{r}0.765 \\
151\end{array}$ & $\begin{array}{l}0.024 p \\
0.004\end{array}$ & $16.92^{*}$ & & & DA8 & $\begin{array}{c}13.8 \mathrm{p} \\
0.4\end{array}$ \\
\hline $\begin{array}{l}1822 \\
0600+735\end{array}$ & $\begin{array}{r}0.793 \\
171\end{array}$ & $\begin{array}{l}0.022 p \\
0.004\end{array}$ & $17.96^{*}$ & & & DC9 & $\begin{array}{c}14.7 p \\
0.4\end{array}$ \\
\hline $\begin{array}{l}2288 \\
1034+078\end{array}$ & $\begin{array}{r}0.735 \\
186\end{array}$ & $\begin{array}{l}0.0187 \\
0.0024\end{array}$ & 19.36 & & 1.20 & $1,-, 1$ & $\begin{array}{r}15.72 \\
0.27\end{array}$ \\
\hline $\begin{array}{l}2542 \\
1214+032\end{array}$ & $\begin{array}{r}0.706 \\
71\end{array}$ & $\begin{array}{l}0.0470 \\
0.0034\end{array}$ & 15.32* & 0.38 & & $\begin{array}{l}* \\
\text { DAs }\end{array}$ & $\begin{array}{r}13.68 \\
0.16\end{array}$ \\
\hline $\begin{array}{l}2696 \\
1310+027\end{array}$ & $\begin{array}{r}0.777 \\
119\end{array}$ & $\begin{array}{l}0.031 \mathrm{p} \\
0.004\end{array}$ & 18.30 & & 1.37 & $1,-, 1$ & $\begin{array}{c}15.7 \mathrm{p} \\
0.3\end{array}$ \\
\hline $\begin{array}{l}3501 \\
1953-011\end{array}$ & $\begin{array}{r}0.790 \\
43\end{array}$ & $\begin{array}{l}0.0864 \\
0.0031\end{array}$ & $\begin{array}{r}13.71 \\
0.05\end{array}$ & $\begin{array}{l}0.30 \\
0.01\end{array}$ & & $\begin{array}{l}3,3,- \\
\text { DA6 }\end{array}$ & $\begin{array}{r}13.39 \\
0.09\end{array}$ \\
\hline
\end{tabular}

LHS1405, and LHS2288 are from preliminary USNO CCD solutions. A "p" denotes photometrically derived parallaxes and $\mathrm{M}_{\mathrm{v}}$ values. The broadband photometric data (with $\mathrm{V}-\mathrm{I}$ on the Kron-Cousins system) were obtained either with a single channel photometer on the 61-in reflector (by Dahn) or with a CCD on the 40-in reflector (by Harris). The numbers of individual $\mathrm{V}, \mathrm{B}-\mathrm{V}$, and V-I observations are specified by n,n,n. The data adopted for LHS1693 and LHS1822 were derived from Greenstein's (1984) MCSP results. The V magnitude for LHS1341 was estimated from unpublished calibrations of $\mathrm{m}_{\mathrm{pg}}$ and $\mathrm{m}_{\mathrm{R}}$ obtained from the LHS Catalogue. Photometric deconvolution of LHS2541/2, a close red dwarf/white dwarf binary, was adopted from Dahn et al. (1976). Where available, spectral types from the McCook and Sion (1987) compilation are included.

Two potential degenerates, the unseen companion responsible for the periodic radial velocity variations reported by Dearborn et al. (1986) for G77-61 (= LHS1555) and LP424-15 $(=$ LHS1986 = WD0807+190), have been explicitly excluded. While the former may well turn 
out to be a cool white dwarf, there is presently insufficient information to even roughly estimate its absolute magnitude. However, it is known from astrometry of G77-61 that the system possesses space velocity components characteristic of the halo population so that the star will make essentially zero contribution to the disk WDLF estimated by the $1 / \mathrm{V}_{\max }$ method. Regarding LP424-15, the only reference to the degenerate nature of this star is that presented by McCook and Sion which is erroneous and no other evidence suggesting a WD - either published or unpublished - could be located.

At this time 71 stars within the 7tenths sample lack the necessary astrometry, photometry, and/or spectroscopy to establish their nature. Figure 1 shows the number distributions of reduced proper motion, $\mathrm{H}_{\mathrm{r}}$, for both the $>8$ tenths and the 7 tenths samples. Since the $>8$ tenths sample

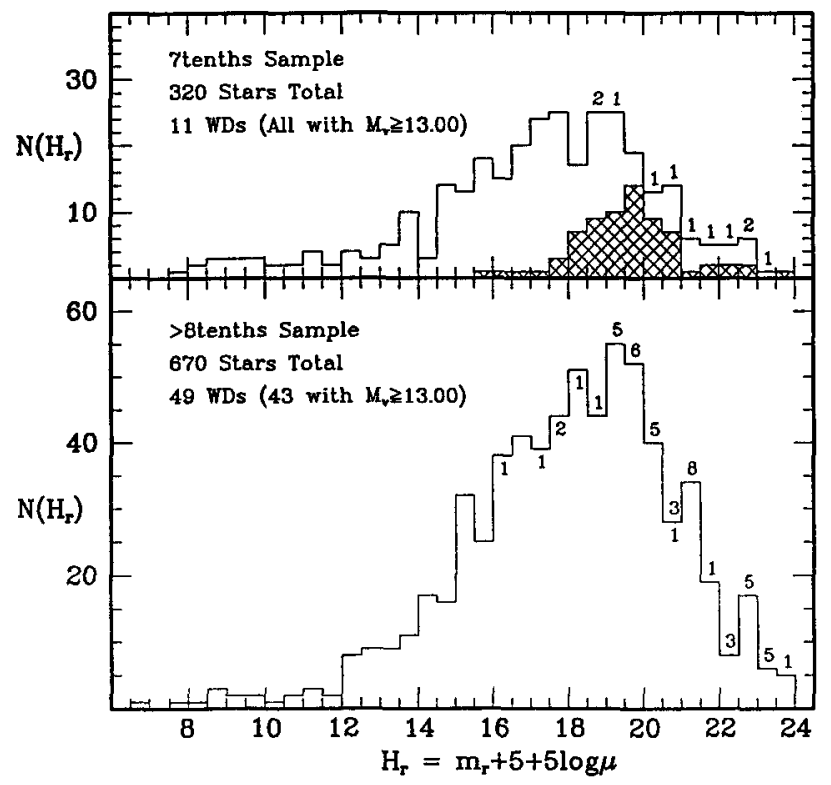

Figure 1. Frequency distributions of reduced proper motion, $H_{r}$, for both the 7tenths and $>8$ tenths samples. Numbers of WDs with either $M_{v} \geq 13.0$ or $M_{v}<13.0$ in each bin are given either above or below the bin tops, respectively. The crosshatch area indicates the 71 unobserved stars.

is complete - that is, the degenerate versus non-degenerate status has been observationally established for all of the >8tenths stars - a comparison of the two distributions should provide an indication of the likelihood of having unidentified WDs among the unobserved sample. Figure 1 reveals that 20 of the $43 \mathrm{cool}$ WDs found in the $>8$ tenths sample have reduced proper motions within the range $18.0 \leq \mathrm{H}_{\mathrm{r}} \leq 21.0-$ just the range within which the 7 tenths sample is seriously incomplete. Consideration of the Luyten color classes of the unobserved stars, however, yields a much more encouraging picture. Table 2 gives the numbers of degenerates and nondegenerates within the relevant $H_{r}$ bins for the various Luyten color classes. The majority of the unobserved 7 tenths stars with $18.0 \leq \mathrm{H}_{\mathrm{r}} \leq \mathbf{2 1 . 0}$ (40 of the total 56) have $\mathrm{m}$ color classes. Based upon the complete $>8$ tenths sample, $\mathrm{m}$ color class degenerates are known to be extremely rare. [In fact, a total of only 3 degenerates are presently recognized among this color class: LP701-29 (= LHS69), 
TABLE 2

Numbers of $>8$ Tenths and 7Tenths Stars by Luyten Color Class

\begin{tabular}{|c|c|c|c|c|c|c|c|c|c|c|}
\hline \multirow{2}{*}{$\begin{array}{l}\mathrm{H}_{\mathrm{r}} \mathrm{Bin} \\
\text { Center }\end{array}$} & \multicolumn{10}{|c|}{ Luyten Color Class } \\
\hline & $\mathbf{a}$ & $a-f$ & $\mathbf{f}$ & $\mathbf{f}-\mathbf{g}$ & $\mathbf{g}$ & $\mathbf{g}-\mathbf{k}$ & $\mathbf{k}$ & $\mathbf{k}-\mathbf{m}$ & $\mathbf{m}$ & $\mathbf{m}+$ \\
\hline & \multicolumn{10}{|c|}{ The >8Tenths Sample (Degenerates/Non-Degenerates) } \\
\hline \multirow{7}{*}{$\begin{array}{l}18.25 \\
18.75 \\
19.25 \\
19.75 \\
20.25 \\
20.75\end{array}$} & $1 / 0$ & & & & & & $0 / 2$ & $0 / 12$ & $0 / 22$ & $0 / 1$ \\
\hline & & & & & & $0 / 3$ & $0 / 3$ & $0 / 3$ & $0 / 27$ & \\
\hline & $2 / 0$ & & & $1 / 0$ & $1 / 0$ & & $0 / 2$ & $0 / 5$ & $0 / 36$ & \\
\hline & $3 / 0$ & & $2 / 0$ & & & & $1 / 3$ & $0 / 9$ & $0 / 34$ & \\
\hline & & $1 / 0$ & $1 / 0$ & & & $2 / 0$ & $1 / 1$ & $0 / 4$ & $0 / 29$ & $0 / 1$ \\
\hline & $2 / 0$ & & & & $1 / 0$ & & $0 / 2$ & $1 / 2$ & $0 / 20$ & \\
\hline & \multicolumn{10}{|c|}{ The 7Tenths Sample (Degenerates/Non-Degenerates/Unknowns) } \\
\hline 18.25 & & & & & & & $0 / 0 / 1$ & $0 / 4 / 2$ & $0 / 6 / 4$ & \\
\hline 18.75 & $2 / 0 / 0$ & & & & & & $0 / 1 / 1$ & $0 / 1 / 3$ & $0 / 11 / 5$ & $0 / 1 / 0$ \\
\hline 19.25 & $1 / 0 / 0$ & $0 / 0 / 1$ & & & & & $0 / 2 / 0$ & $0 / 3 / 2$ & $0 / 9 / 7$ & \\
\hline 19.75 & & & & & & & $0 / 0 / 1$ & $0 / 0 / 2$ & $0 / 5 / 11$ & \\
\hline 20.25 & & & & & & $1 / 0 / 0$ & $0 / 1 / 2$ & $0 / 1 / 0$ & $0 / 1 / 7$ & \\
\hline 20.75 & & $1 / 0 / 0$ & & & & & $0 / 1 / 0$ & $0 / 1 / 1$ & $0 / 4 / 6$ & \\
\hline
\end{tabular}

the unique, highly-blanketed degenerate (Dahn et al. 1978) with $\mathrm{H}_{\mathrm{r}}=22.0$; LP131-66 (= LHS342; Liebert et al. 1979) with $\mathrm{H}_{\mathrm{r}}=22.6$; and LP550-358 (= LHS2288), one of the newly established late-type degenerates reported in this study, with $\mathrm{H}_{\mathrm{r}}=\mathbf{2 3 . 4}$. Note that all three fall well outside of the $\mathrm{H}_{\mathrm{r}}$ range of serious incompleteness for our 7 tenths sample.] The data contained in Table 2 suggests that the 15 unobserved stars with $k$ or $k-m$ colors might include one or possibly two additional degenerates. One unobserved star that is almost assuredly a degenerate is the a-f

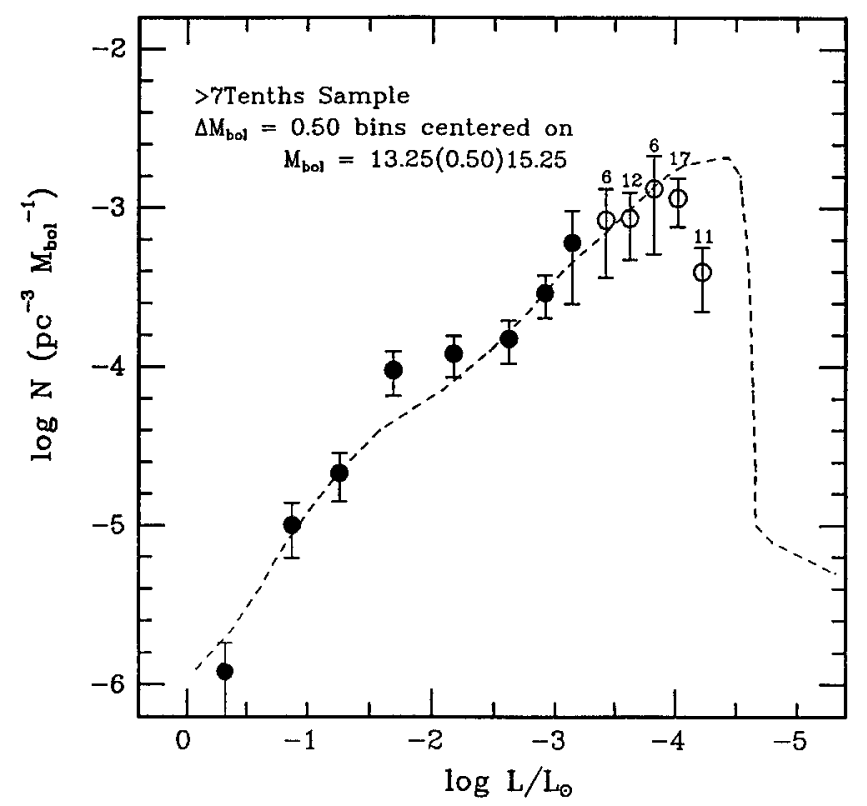

Figure 2. The derived WDLF employing the $>7$ tenths sample degenerates. Filled circles represent the Fleming et al. (1986) data as presented in Liebert et al. (1988) and the dashed curve is the theoretical function of Winget et al. (1987, their Fig. 1). The open circles give the present results where the numbers of stars within each bin are indicated above the error bars. 
color object LP737-47 (= LHS2712) with $\mathrm{H}_{\mathrm{r}}=19.4$. Since this star is relatively bright $(\mathrm{V} \sim 15.0$ according to our unpublished calibrations of the LHS Catalogue $\mathrm{m}_{\mathrm{pg}}$ and $\mathrm{m}_{\mathrm{R}}$ values) it might have a relatively small value of $\mathrm{V}_{\max }$ and therefore make a significant contribution to the space density at whatever $\mathrm{M}_{\text {bol }}$ bin it turns out to occupy. However, based on the blueness of the a-f color class this star most likely has $M_{v}<14.2$ and thus will not affect the cool end of the WDLF. In summary, the arguments presented above suggest that the degenerates listed in Table 1 comprise a very nearly complete subsample of the 7tenths stars - at least for $M_{v}<16.3$.

\section{THE WDLF FROM THE >7TENTHS SAMPLE}

The 7 tenths and $>8$ tenths degenerates together are now referred to as the $>7$ tenths sample. A $1 / \mathrm{V}_{\max }$ analysis identical to that used by Liebert et al. (1988) was performed on the $>7$ tenths degenerates with $M_{v} \geq 13.0$ and the results are presented in Figure 2. Comparing Figure 2 with the results of Liebert et al. (1989) indicates that the present results are fully consistent with the results from the smaller but fully complete sample, at least over the range $-3.3 \geq \log \left(\mathrm{L} / \mathrm{L}_{\odot}\right) \geq-4.3$. Since the 7 tenths subsample is observationally incomplete for the $\mathrm{m}$ color class (which includes degenerates with $M_{v}>16.3$ if they exist at densities detectable within the solar neighborhood), the total absence of stars below $\log \left(\mathrm{L} / \mathrm{L}_{\odot}\right) \sim-4.3$ is based primarily on the Liebert et al. (1988, 1989) results. However, the continued failure to detect such stars within the 7tenths sample does add to the evidence supporting a real turnover in the WDLF at the faint end.

\section{REFERENCES}

Dahn, C. C., Harrington, R. S., Riepe, B. Y., Christy, J. W., Guetter, H. H., Behall, A. L., Walker, R. L., Hewitt, A. V., and Ables, H. D. 1976, Publ. U. S. Naval Observ., Second Series, Vol. XXIV, Part III.

Dahn, C. C., Hintzen, P. M., Liebert, J. W., Stockman, H. S., and Spinrad, H. 1978, Astrophys. J., 219, 979.

Dearborn, D. S. P., Liebert, J., Aaronson, M., Dahn, C. C., Harrington, R., Mould, J. and Greenstein, J. L. 1986, Astrophys. J., 300, 314.

Fleming, T. A., Liebert, J., and Green, R. F. 1986, Astrophys. J., 308, 176.

Greenstein, J. L. 1984, Astrophys. J., 276, 602.

Liebert, J., Dahn, C. C., Gresham, M., Hege, E. K., Moore, R. L., Romanishin, W., and Strittmatter, P. A. 1979, Astrophys. J., 229, 196.

Liebert, J., Dahn, C. C., and Monet, D. G. 1988, Astrophys. J., 332, 891.

Liebert, J., Dahn, C. C., and Monet, D. G. 1989, previous paper in these preceedings

Luyten, W. J. 1979, LHS Catalogue, (Univ. of Minnesota: Minneapolis), 2nd Ed.

McCook, G. P., and Sion, E. M. 1987, Astrophys. J. Suppl., 65, 603.

Winget, D. E., Hansen, C. J., Liebert, J., Van Horn, H. M., Fontaine, G., Nather, R. E., Kepler, S. O., and Lamb, D. Q. 1987, Astrophys. J. (Letters), 315, L77. 